\title{
INTERPOLASI SPLIN KUBIK PERIODIK
}

\author{
WIRA AMLIZA, MAHDHIVAN SYAFWAN, SUSILA BAHRI \\ Program Studi S1 Matematika, \\ Fakultas Matematika dan Ilmu Pengetahuan Alam, Universitas Andalas, \\ Kampus UNAND Limau Manis Padang, Indonesia. \\ email : wiraamliza017@gmail.com,mahdhivan@sci.unand.ac.id,susilabahri@sci.unand.ac.id
}

Diterima 15 Desember 2020 Direvisi 29 Desember 2020 Dipublikasikan 12 Januari 2021

\begin{abstract}
Abstrak. Tulisan ini membahas tentang penurunan interpolasi splin kubik untuk kasus syarat batas periodik dengan lebar selang sebarang. Interpolasi jenis ini digunakan untuk menghampiri data yang memiliki sifat periodik dengan siklus tunggal. Dari hasil simulasi, diperoleh hasil interpolasi yang sangat baik dalam menghampiri data periodik.
\end{abstract}

Kata Kunci: Interpolasi splin kubik, batas periodik

\section{Pendahuluan}

Penentuan nilai taksiran di antara titik-titik data yang diketahui dinamakan masalah pencocokan kurva (curve fitting). Salah satu pendekatan alternatif yang digunakan untuk menyelesaikan masalah pencocokan kurva adalah dengan menerapkan polinomial orde rendah terhadap subkumpulan titik data. Polinomial ini disebut dengan fungsi splin.

Interpolasi splin terdiri dari splin linier, splin kuadratik, dan splin kubik. Splin kubik sering digunakan karena memberikan aproksimasi yang lebih tepat. Meskipun turunan ketiga atau lebih tinggi bisa saja diskontinu, namun hal tersebut biasanya tidak dapat dideteksi secara visual sehingga dapat diabaikan [4].

Tujuan interpolasi splin kubik adalah menurunkan suatu polinomial orde tiga di setiap interval titik data $\left(x_{i}, x_{i+1}\right)$, yaitu

$$
S_{i}(x)=a_{i}\left(x-x_{i}\right)^{3}+b_{i}\left(x-x_{i}\right)^{2}+c_{i}\left(x-x_{i}\right)+d_{i}, i=1,2, \ldots, n,
$$

dimana $a_{i}, b_{i}, c_{i}$ dan $d_{i}$ merupakan koefisien-koefisien yang nilainya akan dicari. Splin kubik terdiri dari beberapa jenis yang dicirikan berdasarkan syarat batasnya, seperti splin kubik alami, splin kubik berujung parabolik, splin kubik berujung pangkat tiga, splin kubik periodik, dan splin kubik terapit. Splin kubik alami dan berujung parabolik untuk lebar selang seragam $\left(h=x_{i+1}-x_{i}\right)$ telah dijelaskan dalam [1]. Splin kubik alami dan berujung parabolik tersebut kemudian dibahas 
secara umum untuk lebar selang sebarang $\left(h_{i}=x_{i+1}-x_{i}\right)$ dalam $[2,5]$. Dalam makalah ini akan dibahas secara khusus splin kubik periodik untuk lebar selang sebarang.

\section{Interpolasi Splin Kubik}

Diberikan $n$ titik data di bidang- $x y$,

$$
\left(x_{1}, y_{1}\right),\left(x_{2}, y_{2}\right), \cdots,\left(x_{n}, y_{n}\right)
$$

yang nilai-nilainya diketahui. Titik-titik data ini diinterpolasi dengan menggunakan metode splin kubik, yaitu dengan membangun fungsi

$$
S(x)= \begin{cases}S_{1}(x), & x_{1} \leq x \leq x_{2} \\ S_{2}(x), & x_{2} \leq x \leq x_{3} \\ \vdots & \\ S_{n-1}(x), & x_{n-1} \leq x \leq x_{n}\end{cases}
$$

dimana $S_{i}(x), i=1,2, \cdots, n-1$, adalah polinomial kubik yang didefinisikan oleh

$$
S_{i}(x)=a_{i}\left(x-x_{i}\right)^{3}+b_{i}\left(x-x_{i}\right)^{2}+c_{i}\left(x-x_{i}\right)+d_{i}, x_{i} \leq x \leq x_{i+1}
$$

dengan $a_{i}, b_{i}, c_{i}$, dan $d_{i}$ adalah koefisien yang nilai-nilainya akan dicari.

Teorema berikut memberikan nilai-nilai dari koefisien $a_{i}, b_{i}, c_{i}$ dan $d_{i}$ yang merupakan perumuman dari Teorema Interpolasi Splin Kubik dengan $h_{i}=x_{i+1}-x_{i}$, $i=1,2, \cdots, n-1$.

Teorema 2.1. [1] (Interpolasi Splin Kubik) Diberikan $n$ titik data $\left(x_{1}, y_{1}\right),\left(x_{2}, y_{2}\right)$, $\cdots,\left(x_{n}, y_{n}\right)$ dengan $h_{i}=x_{i+1}-x_{i}, i=1,2, \cdots, n-1$, Splin kubik

$$
S(x)= \begin{cases}a_{1}\left(x-x_{1}\right)^{3}+b_{1}\left(x-x_{1}\right)^{2}+c_{1}\left(x-x_{1}\right)+d_{1}, & x_{1} \leq x \leq x_{2} \\ a_{2}\left(x-x_{2}\right)^{3}+b_{2}\left(x-x_{2}\right)^{2}+c_{2}\left(x-x_{2}\right)+d_{2}, & x_{2} \leq x \leq x_{3} \\ \vdots & \\ a_{n-1}\left(x-x_{n-1}\right)^{3}+b_{n-1}\left(x-x_{n-1}\right)^{2}+c_{n-1}\left(x-x_{n-1}\right)+d_{n-1}, & x_{n-1} \leq x \leq x_{n}\end{cases}
$$

yang menginterpolasi titik-titik tersebut, mempunyai koefisien-koefisien yang dinyatakan dengan

$$
\begin{aligned}
a_{i} & =\frac{M_{i+1}-M_{i}}{6 h_{i}} \\
b_{i} & =\frac{M_{i}}{2} \\
c_{i} & =\frac{y_{i+1}-y_{i}}{h_{i}}-\left[\frac{M_{i+1}+2 M_{i}}{6}\right] h_{i} \\
d_{i} & =y_{i}
\end{aligned}
$$

untuk $i=1,2, \cdots, n-1$, di mana $M_{i}=S^{\prime \prime}\left(x_{i}\right), i=1,2, \cdots, n$

Bukti. Persamaan (2.2) dapat ditulis dalam persamaan (2.1) sebagai berikut:

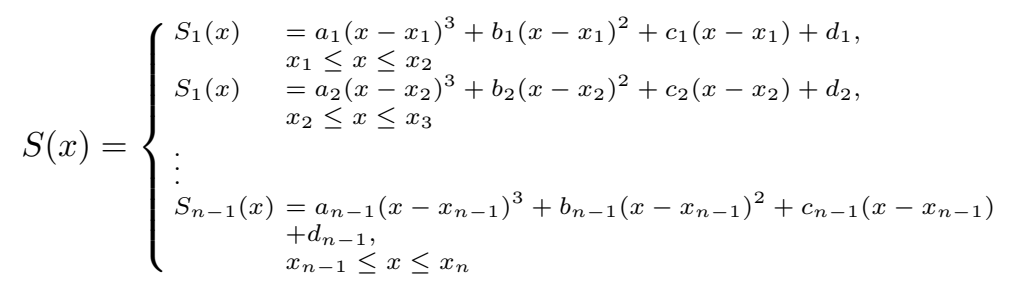


Turunan pertama dari $S(x)$ adalah

$$
S^{\prime}(x)= \begin{cases}S_{1}^{\prime}(x)=\quad 3 a_{1}\left(x-x_{1}\right)^{2}+2 b_{1}\left(x-x_{1}\right)+c_{1}, \\
x_{1} \leq x \leq x_{2} \\
S_{2}^{\prime}(x)=\begin{array}{l}
3 a_{2}\left(x-x_{2}\right)^{2}+2 b_{2}\left(x-x_{2}\right)+c_{2}, \\
\\
x_{2} \leq x \leq x_{3}
\end{array} \\
\vdots \\
S_{n-1}^{\prime}(x)=3 a_{n-1}\left(x-x_{n-1}\right)^{2}+2 b_{n-1}\left(x-x_{n-1}\right)+c_{n-1}, \\
x_{n-1} \leq x \leq x_{n}\end{cases}
$$

dan turunan kedua dari $S(x)$ adalah

$$
S^{\prime \prime}(x)= \begin{cases}S_{1}^{\prime \prime}(x)=\quad & 6 a_{1}\left(x-x_{1}\right)+2 b_{1} \\ & x_{1} \leq x \leq x_{2} \\ S_{2}^{\prime \prime}(x)=\quad & 6 a_{2}\left(x-x_{2}\right)+2 b_{2} \\ & x_{2} \leq x \leq x_{3} \\ \vdots & \\ S_{n-1}^{\prime \prime}(x)= & 6 a_{n-1}\left(x-x_{n-1}\right)+2 b_{n-1} \\ & x_{n-1} \leq x \leq x_{n}\end{cases}
$$

Selanjutnya persamaan $(2.4),(2.5),(2.6)$ memenuhi keempat sifat berikut:

(1) $S(x)$ melalui seluruh titik-titik data yang diketahui,

(2) $S(x)$ kontinu pada interval $\left[x_{1}, x_{n}\right]$,

(3) $S^{\prime}(x)$ kontinu pada interval $\left[x_{1}, x_{n}\right]$,

(4) $S^{\prime \prime}(x)$ kontinu pada interval $\left[x_{1}, x_{n}\right]$.

Keempat sifat splin di atas akan digunakan untuk menentukan koefisien $a_{i}, b_{i}, c_{i}$ dan $d_{i}, i=1,2, \cdots, n-1$.

(1) $S(x)$ melalui seluruh titik-titik data yang diketahui Karena $S(x)$ melalui seluruh titik data $\left(x_{i}, y_{i}\right), i=1,2, \cdots, n$, maka berlaku

$$
S\left(x_{1}\right)=y_{1}, S\left(x_{2}\right)=y_{2}, \cdots, S\left(x_{n}\right)=y_{n} .
$$

Karena $x_{i} \in\left[x_{i}, x_{i+1}\right]$ dari persamaan (2.1) dan (2.2) didapatkan $S\left(x_{i}\right)=$ $S_{i}\left(x_{i}\right)=d_{i}$ dengan menggunakan $n-1$ persamaan pertama pada persamaan (2.7), diperoleh

$$
d_{i}=y_{i}, i=1,2, \cdots, n-1 \text {. }
$$

Selanjutnya, dengan menggunakan persamaan terakhir pada persamaan (2.1) dan persamaan (2.2) untuk $x=x_{n}$, dapat ditulis

$$
\begin{aligned}
S\left(x_{n}\right)=S_{n-1}\left(x_{n}\right)= & a_{n-1}\left(x_{n}-x_{n-1}\right)^{3}+b_{n-1}\left(x_{n}-x_{n-1}\right)^{2} \\
& +c_{n-1}\left(x_{n}-x_{n-1}\right)+d_{n-1} .
\end{aligned}
$$

Dengan menggunakan persamaan terakhir pada persamaan (2.7), maka persamaan (2.9) dapat ditulis

$$
a_{n-1} h_{n-1}^{3}+b_{n-1} h_{n-1}^{2}+c_{n-1} h_{n-1}+d_{n-1}=y_{n},
$$

dengan $h_{n-1}=x_{n}-x_{n-1}$. 
(2) $S(x)$ kontinu pada interval $\left[x_{1}, x_{n}\right]$ Karena $S(x)$ kontinu pada $x_{1} \leq x \leq x_{n}$, maka untuk setiap titik $x_{i}$ pada $x_{2}, x_{3}, \cdots, x_{n-1}$, berlaku

$$
S_{i}\left(x_{i+1}\right)=S_{i+1}\left(x_{i+1}\right), \quad i=1,2, \cdots, n-2 .
$$

Dengan menggunakan $S_{i}\left(x_{i}\right)=y_{i}$ dan persamaan (2.11) diperoleh

$$
S_{i}\left(x_{i+1}\right)=y_{i+1}, \quad i=2,3, \cdots, n-1 .
$$

Selanjutnya dengan menggunakan persamaan (2.4), maka persamaan (2.12) menjadi

$$
\begin{gathered}
a_{1} h_{1}^{3}+b_{1} h_{1}^{2}+c_{1} h_{1}+d_{1}=y_{2}, \\
\vdots \\
a_{n-2} h_{n-2}^{3}+b_{n-2} h_{n-2}^{2}+c_{n-2} h_{n-2}+d_{n-2}=y_{n-1},
\end{gathered}
$$

dengan $h_{i}=x_{i+1}-x_{i}, i=1,2, \cdots, n-2$. Dari persamaan (2.10) dan (2.13) dapat dibuat hubungan berikut:

$$
a_{i} h_{i}^{3}+b_{i} h_{i}^{2}+c_{i} h_{i}+d_{i}=y_{i+1}, \quad i=1,2, \cdots, n-1 .
$$

(3) $S^{\prime}(x)$ kontinu pada interval $\left[x_{1}, x_{n}\right]$ Karena $S^{\prime}(x)$ kontinu pada $x_{1} \leq x \leq x_{n}$, maka untuk tiap titik-titik interior pada $x_{2}, x_{3}, \cdots, x_{n-1}$, berlaku

$$
S_{i}^{\prime}\left(x_{i+1}\right)=S_{i+1}^{\prime}\left(x_{i+1}\right), i=1,2, \cdots, n-2 .
$$

Dari persamaan (2.5), diketahui bahwa

$$
S_{i}^{\prime}\left(x_{i}\right)=c_{i}, i=1,2, \cdots, n-1
$$

Substitusikan persamaan (2.5) ke ruas kiri persamaan (2.15) dan substitusikan persamaan (2.16) ke ruas kanan persamaan (2.15), maka diperoleh

$$
3 a_{i} h_{i}^{2}+2 b_{i} h_{i}+c_{i}=c_{i+1}, \quad i=1,2, \cdots, n-2 .
$$

dimana $h_{n-1}=x_{n}-x_{n-1}$.

(4) $S^{\prime \prime}(x)$ kontinu pada interval $\left[x_{1}, x_{n}\right]$ Karena $S^{\prime \prime}(x)$ kontinu untuk $x_{1} \leq x \leq x_{n}$, maka untuk tiap titik-titik interior pada $x_{2}, x_{3}, \cdots, x_{n-1}$, berlaku

$$
S_{i}^{\prime \prime}\left(x_{i+1}\right)=S_{i+1}^{\prime \prime}\left(x_{i+1}\right), i=1,2, \cdots, n-2 .
$$

Dari persamaan (2.6), diketahui bahwa

$$
S_{i}^{\prime \prime}\left(x_{i}\right)=2 b_{i}, i=1,2, \cdots, n-1
$$

Substitusikan persamaan (2.6) ke ruas kiri persamaan (2.18) dan (2.19) ke ruas kanan persamaan (2.18), diperoleh

$$
6 a_{i} h_{i}+2 b_{i}=2 b_{i+1}, \quad i=1,2, \cdots, n-2
$$

dimana $h_{i}=x_{i+1}-x_{i}$. 
Persamaan-persamaan $(2.8),(2.14),(2.17)$ dan (2.20) membentuk sebuah sistem dengan $4 n-6$ persamaan linier. Sementara itu persamaan (2.14) memberikan $4 n-4$ koefisien-koefisien yang tak diketahui untuk $a_{i}, b_{i}, c_{i}$ dan $d_{i}, i=1,2, \cdots$, $n-1$. Akibatnya, diperlukan dua persamaan tambahan untuk menentukan koefisienkoefisien tersebut. Untuk mempermudah penulisan, misalkan

$$
M_{i}=S^{\prime \prime}\left(x_{i}\right), i=1,2, \cdots, n .
$$

Dengan mensubstitusikan persamaan (2.19) ke persamaan (2.21), diperoleh

$$
M_{i}=2 b_{i}, i=1,2, \cdots, n-1
$$

atau

$$
b_{i}=\frac{M_{i}}{2}, i=1,2, \cdots, n-1 .
$$

Substitusikan nilai $b_{i}$ pada persamaan (2.22) ke persamaan (2.20), dan sebelumnya telah diketahui bahwa pada persamaan (2.18) dan (2.19) maka $2 b_{i+1}=$ $S_{i}^{\prime \prime}\left(x_{i+1}\right)$, sehingga

$$
6 a_{i} h_{i}+M_{i}=S_{i}^{\prime \prime}\left(x_{i+1}\right)
$$

Karena $S_{i}^{\prime \prime}\left(x_{i+1}\right)=S^{\prime \prime}\left(x_{i+1}\right)$ dan persamaan $(2.21)$, maka

$$
a_{i}=\frac{M_{i+1}-M_{i}}{6 h_{i}}, i=1,2, \cdots, n-2 .
$$

dengan menggunakan persamaan terakhir pada persamaan (2.6) untuk $x=x_{n}$ dan substitusikan nilai $b_{i}$ dengan $i=n-1$ pada persamaan (2.22) ke persamaan di atas dan $h_{n-1}=x_{n}-x_{n-1}$ serta $S^{\prime \prime}\left(x_{n}\right)=M_{n}$, maka

$$
a_{n-1}=\frac{M_{n}-M_{n-1}}{6 h_{n-2}} .
$$

Dari persamaan (2.23) dan (2.24) dapat ditulis kembali

$$
a_{i}=\frac{M_{i+1}-M_{i}}{6 h_{i}}, i=1,2, \cdots, n-1 .
$$

Dari persamaan (2.23) dan (2.24) dapat ditulis kembali

$$
a_{i}=\frac{M_{i+1}-M_{i}}{6 h_{i}}, i=1,2, \cdots, n-1 .
$$

Terakhir, dengan mensubstitusikan nilai a,b dan d masing-masing pada persamaan (2.26), (2.22) dan (2.8) ke persamaan (2.14), diperoleh

$$
c_{i}=\frac{y_{i+1}-y_{i}}{h_{i}}-\left[\frac{M_{i+1}+2 M_{i}}{6}\right] h_{i}, i=1,2, \cdots, n-1
$$

Perhatikan bahwa nilai-nilai koefisien $a_{i}, b_{i}$ dan $c_{i}$ bergantung pada nilai $M_{i}$, $i=1,2, \cdots, n$ yang belum diketahui. Nilai-nilai $M_{i}$ tersebut dapat dicari dengan mensubstitusikan koefisien $a_{i}, b_{i}$ dan $c_{i}$ pada persamaan (2.17), sehingga diperoleh

$$
\begin{aligned}
6\left[\frac{y_{i+2}-y_{i+1}}{h_{i+1}}-\frac{y_{i+1}-y_{i}}{h_{i}}\right]= & h_{i} M_{i}+2\left(h_{i}+h_{i+1}\right) M_{i+1} \\
& +h_{i+1} M_{i+2}
\end{aligned}
$$


dengan $i=1,2, \cdots, n-2$.

Persamaan (2.28) dapat ditulis kembali dalam bentuk matriks,

$$
H \mathbf{m}=6 \mathbf{k},
$$

dimana

$$
\begin{aligned}
& H=\left[\begin{array}{ccccccc}
h_{1} & 2\left(h_{1}+h_{2}\right) & h_{2} & \ldots & 0 & 0 & 0 \\
0 & h_{2} & 2\left(h_{2}+h_{3}\right) & \cdots & 0 & 0 & 0 \\
\vdots & \ddots & \ddots & \ddots & \ddots & \vdots & \\
0 & 0 & 0 & \cdots & 2\left(h_{n-3}+h_{n-2}\right) & h_{n-2} & 0 \\
0 & 0 & 0 & \cdots & h_{n-2} & 2\left(h_{n-2}+h_{n-1}\right) & h_{n-1}
\end{array}\right], \\
& \mathbf{m}=\left[\begin{array}{c}
M_{1} \\
M_{2} \\
\vdots \\
M_{n-1} \\
M_{n}
\end{array}\right], \mathbf{k}=\left[\begin{array}{c}
\frac{y_{3}-y_{2}}{h_{2}}-\frac{y_{2}-y_{1}}{h_{1}} \\
\frac{y_{4}-y_{3}}{h_{3}}-\frac{y_{3}-y_{2}}{h_{2}} \\
\vdots \\
\frac{y_{n-1}-y_{n-2}}{h_{2}}-\frac{y_{n-2}-y_{n-3}}{h_{n-3}} \\
\frac{y_{n}-y_{n-1}}{h_{n-1}}-\frac{y_{n-1}-y_{n-2}}{h_{n-2}}
\end{array}\right] .
\end{aligned}
$$

\section{Splin Periodik}

Splin periodik digunakan untuk menginterpolasi titik-titik $\left(x_{1}, y_{1}\right),\left(x_{2}, y_{2}\right), \cdots$, $\left(x_{n}, y_{n}\right)$ yang diasumsikan berada pada siklus tunggal dari kurva periodik (satu periode) dengan periode $x_{n}-x_{1}$. Dengan demikian splin periodik memenuhi syarat batas berikut :

$$
\begin{aligned}
S\left(x_{1}\right) & =S\left(x_{n}\right), \\
S^{\prime}\left(x_{1}\right) & =S^{\prime}\left(x_{n}\right), \\
S^{\prime \prime}\left(x_{1}\right) & =S^{\prime \prime}\left(x_{n}\right) .
\end{aligned}
$$

Berdasarkan persamaan (2.7) dan syarat batas (3.1), diperoleh

$$
y_{1}=y_{n} .
$$

Karena telah dimisalkan $S_{i}^{\prime \prime}(x)=M_{i}$ maka syarat batas (3.3) dapat ditulis ulang menjadi

$$
M_{1}=M_{n} .
$$

Selanjutnya berdasarkan persamaan (2.16) dan syarat batas (3.2), diperoleh

$$
S^{\prime}\left(x_{1}\right)=c_{1} .
$$

Dari persamaan (2.17) dihasilkan $S_{i+1}^{\prime}\left(x_{i+1}\right)=c_{i+1}$, sehingga dengan persamaan (2.5) untuk $x=x_{n}$ dan syarat batas (3.2), diperoleh

$$
S^{\prime}\left(x_{n}\right)=S_{n-1}^{\prime}\left(x_{n}\right)=3 a_{n-1} h_{n-1}^{2}+2 b_{n-1} h_{n-1}+c_{n-1},
$$

dengan $h_{n-1}=x_{n}-x_{n-1}$. Substitusikan persamaan (3.6) dan (3.7) ke syarat batas (3.2) serta gunakan nilai koefisien pada persamaan (2.3), sehingga diperoleh

$$
\begin{aligned}
\frac{y_{2}-y_{1}}{h_{1}}-\frac{y_{n}-y_{n-1}}{h_{n-1}}= & \frac{h_{1} M_{2}}{6}+\frac{2 h_{1} M_{1}}{6}-\frac{h_{n-1} M_{n}}{6} \\
& -\frac{2 h_{n-1} M_{n-1}}{6}+\frac{6 h_{n-1} M_{n-1}}{6} \\
& +\frac{3 h_{n-1} M_{n}}{6}-\frac{3 h_{n-1} M_{n-1}}{6} .
\end{aligned}
$$


Substitusikan persamaan (3.4) dan (3.5) ke persamaan (3.8), diperoleh

$$
\begin{aligned}
6\left[\frac{y_{2}-y_{1}}{h_{1}}-\frac{y_{1}-y_{n-1}}{h_{n-1}}\right]= & 2\left(h_{1}+h_{n-1}\right) M_{1}+h_{1} M_{2} \\
& +h_{n-1} M_{n-1} .
\end{aligned}
$$

Perhatikan persamaan (2.17) untuk $i=n-2$ dan menggunakan koefisien pada persamaan (2.3), maka

$$
\begin{aligned}
\frac{y_{n}-y_{n-1}}{h_{n-1}}-\frac{y_{n-1}-y_{n-2}}{h_{n-2}}= & \frac{h_{n-1} M_{n}}{6}+\frac{2 h_{n-1} M_{n-1}}{6}-\frac{h_{n-2} M_{n-1}}{6} \\
& -\frac{2 h_{n-2} M_{n-2}}{6}+\frac{6 h_{n-2} M_{n-2}}{6} \\
& +\frac{3 h_{n-2} M_{n-1}}{6}-\frac{3 h_{n-2} M_{n-2}}{6} .
\end{aligned}
$$

Substitusikan persamaan (3.4) dan (3.5) ke persamaan (3.10), sehingga

$$
\begin{aligned}
6\left[\frac{y_{1}-y_{n-1}}{h_{n-1}}-\frac{y_{n-1}-y_{n-2}}{h_{n-2}}\right]= & h_{n-1} M_{1}+h_{n-2} M_{n-2} \\
& +2\left(h_{n-1}+h_{n-2}\right) M_{n-1} .
\end{aligned}
$$

Dengan menambahkan persamaan (3.5), (3.9), dan (3.11) ke persamaan (2.28), dapat ditulis dalam bentuk matriks berikut:

$$
H_{2} \mathbf{m}=6 \mathbf{k}
$$

dimana

$$
\begin{gathered}
H_{2}=\left[\begin{array}{cccccc}
2\left(h_{1}+h_{n-1}\right) & h_{1} & 0 & \cdots & 0 & h_{n-1} \\
h_{1} & 2\left(h_{1}+h_{2}\right) & h_{2} & \cdots & 0 & 0 \\
0 & h_{2} & 2\left(h_{2}+h_{3}\right) & \cdots & 0 & 0 \\
\vdots & \ddots & \ddots & \ddots & \ddots & \vdots \\
0 & 0 & 0 & \cdots & h_{n-3} & 0 \\
h_{n-1} & 0 & 0 & \cdots & 2\left(h_{n-3}+h_{n-2}\right) & h_{n-2} \\
h_{n-2} & 2\left(h_{n-2}+h_{n-1}\right)
\end{array}\right] \\
\mathbf{m}=\left[\begin{array}{c}
M_{1} \\
M_{2} \\
\vdots \\
M_{n-2} \\
M_{n-1}
\end{array}\right], \mathbf{k}=\left[\begin{array}{c}
\frac{y_{2}-y_{1}}{h_{1}-\frac{y_{1}-y_{n-1}}{h_{n-1}}} \\
\frac{y_{3}-y_{2}}{h_{2}}-\frac{y_{2}-y_{1}}{h_{1}} \\
\frac{y_{n-1}-y_{n-2}}{h_{n-2}}-\frac{y_{n-2}-y_{n-3}}{h_{n-3}} \\
\frac{y_{1}-y_{n-1}}{h_{n-1}}-\frac{y_{n-1}-y_{n-2}}{h_{n-2}}
\end{array}\right] .
\end{gathered}
$$

\section{Contoh Kasus}

Diberikan titik-titik data pada Tabel 1 yang dibangkitkan dari fungsi $f(x)=\sin (x)$ pada $[0,2 \pi]$. Titik-titik data tersebut akan diinterpolasi dengan fungsi splin periodik sehingga menghasilkan kurva yang mulus.

Dari Tabel 1, maka banyak titik data yang akan diinterpolasi adalah $n=5$. Selanjutnya substitusikan nilai-nilai pada Tabel 1 ke persamaan (3.12) diperoleh 
Tabel 1. Titik-Titik Data Fungsi Periodik

\begin{tabular}{|c|c|c|c|c|c|}
\hline$x$ & 0 & $\frac{\pi}{2}$ & $\frac{5 \pi}{6}$ & $\frac{3 \pi}{2}$ & $2 \pi$ \\
\hline$y$ & 0 & 1 & $\frac{1}{2}$ & -1 & 0 \\
\hline$h$ & $\frac{\pi}{2}$ & $\frac{\pi}{3}$ & $\frac{2 \pi}{3}$ & $\frac{\pi}{2}$ & \\
\hline
\end{tabular}

sistem persamaan berikut:

$$
\left[\begin{array}{cccc}
2 \pi & \frac{\pi}{2} & 0 & \frac{\pi}{2} \\
\frac{\pi}{2} & \frac{5 \pi}{3} & \frac{\pi}{3} & 0 \\
0 & \frac{\pi}{3} & 2 \pi & \frac{2 \pi}{3} \\
\frac{\pi}{2} & 0 & \frac{2 \pi}{3} & \frac{7 \pi}{3}
\end{array}\right]\left[\begin{array}{l}
M_{1} \\
M_{2} \\
M_{3} \\
M_{4}
\end{array}\right]=6\left[\begin{array}{c}
0 \\
\frac{-21}{\pi} \\
\frac{-9}{2 \pi} \\
\frac{51}{2 \pi}
\end{array}\right]
$$

Akan dicari nilai $M_{1}, M_{2}, M_{3}$ dan $M_{4}$ dengan menggunakan operasi invers pada aplikasi MATLAB, sehingga diperoleh

$$
\left[\begin{array}{l}
M_{1} \\
M_{2} \\
M_{3} \\
M_{4}
\end{array}\right]=\left[\begin{array}{c}
-0.0131 \\
-1.1841 \\
-0.4428 \\
1.2366
\end{array}\right]
$$

Karena syarat batas splin periodik, sehingga $M_{1}=M_{5}=-0.0131$.

Selanjutnya akan dicari nilai-nilai koefisien $a_{i}, b_{i}, c_{i}$ dan $d_{i}$, sehingga

(1) $a_{i}=\frac{M_{i+1}-M_{i}}{6 h_{i}}$, maka

$a_{1}=-0.1242, a_{2}=0.118, a_{3}=0.1336$, dan $a_{4}=-0.1326$.

(2) $b_{i}=\frac{M_{i}}{2}$, maka

$b_{1}=-0.0066, b_{2}=-0.592, b_{3}=-0.2214$, dan $b_{4}=0.6183$

(3) $c_{i}=\frac{y_{i+1}-y_{i}}{h_{i}}-\left[\frac{M_{i+1}+2 M_{i}}{6}\right] h_{i}$, maka

$c_{1}=0.9535, c_{2}=0.0131, c_{3}=-0.8387$, dan $c_{4}=-0.0074$.

(4) $d_{i}=y_{i}$, maka

$d_{1}=0, d_{2}=1, d_{3}=\frac{1}{2}$, dan $d_{4}=-1$. 
Koefisien yang telah diperoleh, disubstitusikan ke persamaan (2.1), sehingga

$$
S(x)=\left\{\begin{aligned}
& S_{1}(x)=-0.1242(x-0)^{3}-0.0066(x-0)^{2}+0.9535(x-0), \\
& 0 \leq x \leq \frac{\pi}{2} \\
& S_{2}(x)=0.118\left(x-\frac{\pi}{2}\right)^{3}-0.592\left(x-\frac{\pi}{2}\right)^{2}+0.0131\left(x-\frac{\pi}{2}\right)+1, \\
& \frac{\pi}{2} \leq x \leq \frac{5 \pi}{6} 5 \pi \\
& S_{3}(x)=0.1336\left(x-\frac{5 \pi}{6}\right)^{3}-0.2214\left(x-\frac{5 \pi}{6}\right)^{2}-0.8387\left(x-\frac{5 \pi}{6}\right)+\frac{1}{2}, \\
& \frac{5 \pi}{6} \leq x \leq \frac{3 \pi}{2} \\
& S_{4}(x)=0.1326\left(x-\frac{3 \pi}{2}\right)^{3}+0.6183\left(x-\frac{3 \pi}{2}\right)^{2}-0.0074\left(x-\frac{3 \pi}{2}\right)-1, \\
& \frac{3 \pi}{2} \leq x \leq 2 \pi
\end{aligned}\right.
$$

Dengan menggunakan aplikasi Matlab, kurva splin kubik periodik dan kurva fungsi sinus diplot dalam satu gambar, maka akan terlihat seperti pada Gambar 1. Dari gambar dapat dilihat bahwa kurva splin kubik dapat mengaproksimasi kurva fungsi sinus dengan cukup baik.

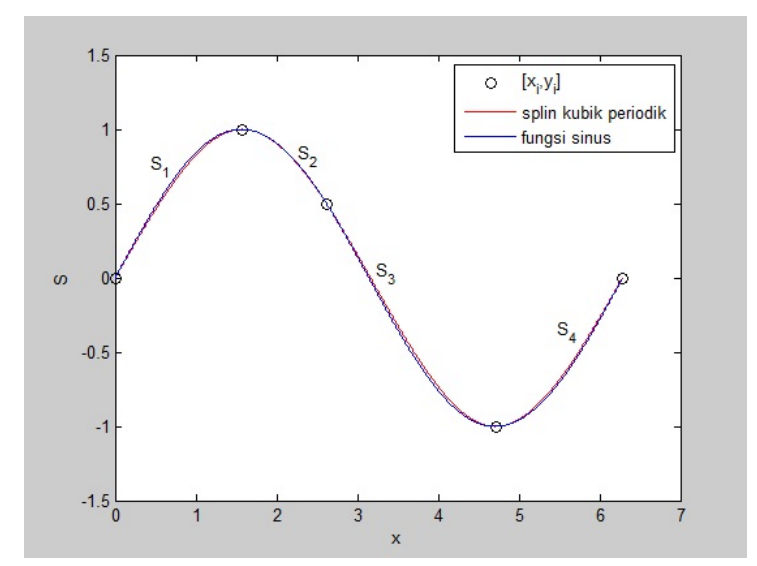

Gambar 1. Kurva Splin Kubik Periodik dan Kurva Sinus Digabungkan

\section{Kesimpulan}

Dari penelitian yang telah dilakukan, dapat disimpulkan bahwa :

(1) Fungsi splin kubik $S(x)$

$$
S(x)=\left\{\begin{array}{l}
a_{1}\left(x-x_{1}\right)^{3}+b_{1}\left(x-x_{1}\right)^{2}+c_{1}\left(x-x_{1}\right)+d_{1}, \\
x_{1} \leq x \leq x_{2} \\
a_{2}\left(x-x_{2}\right)^{3}+b_{2}\left(x-x_{2}\right)^{2}+c_{2}\left(x-x_{2}\right)+d_{2}, \\
x_{2} \leq x \leq x_{3} \\
\vdots \\
a_{n-1}\left(x-x_{n-1}\right)^{3}+b_{n-1}\left(x-x_{n-1}\right)^{2}+c_{n-1}\left(x-x_{n-1}\right)+d_{n-1}, \\
x_{n-1} \leq x \leq x_{n}
\end{array}\right.
$$


memenuhi sifat-sifat berikut :

(a) $S(x)$ melalui seluruh titik-titik data yang diketahui,

(b) $S(x)$ kontinu pada interval $\left[x_{1}, x_{n}\right]$,

(c) $S^{\prime}(x)$ kontinu pada interval $\left[x_{1}, x_{n}\right]$,

(d) $S^{\prime \prime}(x)$ kontinu pada interval $\left[x_{1}, x_{n}\right]$.

Dari keempat sifat-sifat di atas dapat diperoleh nilai-nilai koefisien $a_{i}, b_{i}, c_{i}$ dan $d_{i}$.

(2) Splin kubik periodik memiliki tiga syarat batas, yaitu:
(a) $S\left(x_{1}\right)=S\left(x_{n}\right)$,
(b) $S^{\prime}\left(x_{1}\right)=S^{\prime}\left(x_{n}\right)$,
(c) $S^{\prime \prime}\left(x_{1}\right)=S^{\prime \prime}\left(x_{n}\right)$.

Dari ketiga syarat batas tersebut diperoleh :

(a) $y_{1}=y_{n}$,

(b) $M_{1}=M_{2}$,

(c) $6\left[\frac{y_{2}-y_{1}}{h_{1}}-\frac{y_{1}-y_{n-1}}{h_{n-1}}\right]=2\left(h_{1}+h_{n-1}\right) M_{1}+h_{1} M_{2}+h_{n-1} M_{n-1}$, dimana $M_{i}=S_{i}^{\prime \prime}(x), i=1,2, \cdots, n$.

(3) Penambahan syarat batas splin periodik di atas menghasilkan sistem persamaan matriks berukuran $(n-1) \times(n-1)$.

(4) Penggunaan interpolasi splin kubik periodik cukup baik dalam menghampiri data yang memiliki sifat periodik dengan siklus tunggal.

\section{Ucapan Terima Kasih}

Penulis mengucapkan terima kasih kepada ibu Lyra Yulianti, ibu Riri Lestari dan ibu Yanita yang telah memberikan masukan dan saran sehingga makalah ini dapat diselesaikan dengan baik.

\section{Daftar Pustaka}

[1] Anton, H. and C. Rorres. 20013. Elementary Linear Algebra, Applications Version. Edisi ke-11. Wiley. New York.

[2] Syafwan, E. 2011. Aplikasi Matriks Tridiagonal Pada Interpolasi Splin Kubik. Skripsi S-1. Universitas Andalas.

[3] Purcell, E.J. dan D. Varberg. 1999. Kalkulus dan Geometri Analitis Edisi ke-5 jilid 1. Alih Bahasa : I Nyoman Susila, Bana Kartasasmita, Rawuh. Erlangga. Jakarta.

[4] Schied, F. 1992. Analisis Numerik. Alih Bahasa: Pantur Silaban. Erlangga. Jakarta.

[5] Mathews, John H., K.D. Fink. 1992. Numerical Methods for Computer Science. Engineering, and Mathematics. Edisi ke-2. Prentice-Hall, Englewood Cliffs. 